\title{
HERANÇAS GRÁFICAS QUE DERAM ORIGEM AO LIVRO DE IMAGEM
}

\author{
GRAPHIC LEGACIES THAT GAVE RISE TO WORDLESS PICTUREBOOKS
}

\author{
Hanna ARAÚJO \\ UFAC \\ mailprahanna@gmail.com \\ Lucia REILY \\ Unicamp \\ lureily@terra.com.br
}

\begin{abstract}
Resumo: O livro de imagem é uma produção editorial na qual a narrativa é alicerçada e conduzida pela sequência de imagens. No Brasil, a partir da década de 1970, houve o aparecimento deste gênero e sua produção tem aumentado a cada ano. Este artigo busca evidenciar as origens e heranças gráficas, nacionais e internacionais, que culminaram com o desenvolvimento da narrativa visual. Busca demonstrar a partir de diversos exemplos como os conteúdos das histórias variam de acordo com a época e a concepção de infância em vigor, reveladas a partir de alguns exemplos.
\end{abstract}

Palavras-chave: Livro de imagem. Narrativa visual. Processo de criação.

Abstract: Picture books are an editorial genre in which the narrative is scaffolded and conducted through a sequence of images. This kind of production was inaugurated in Brazil in the 1970s increasing year by year from then on. This article aims to discuss theinternational and national graphic origins and legacy that led to the development of visual narration in our country. By using several historical examples, our intention is to demonstrate how the content of the stories varied according to the times when they were produced and how the storylines relate to existing conceptions of childhood.

Keywords: Picture books. Visual narrative. Creative process.

\section{Introdução}

O livro de imagem é uma produção editorial enquadrada corriqueiramente como literatura para crianças. Dada a natureza do objeto -narrativas visuais sustentadas e conduzidas de maneira autônoma pela imagem - é entendido como um livro de leitura mais simples, dada a ausência do texto escrito. Nesta perspectiva, tornam-se evidentes duas concepções subjacentes: 1) esses livros 
são próprios para crianças, porque a leitura das imagens pode ser realizada por elas, inclusive por aquelas que ainda não foram alfabetizadas; 2) esses livros são menos importantes e têm menos valor que aqueles que portam texto, em razão da presença da imagem sem o suporte da palavra escrita. A análise aprofundada de uma variedade de livros de imagem da indústria cultural brasileira e internacional mostra que ambas as concepções são equivocadas.

É verdade que as crianças se sentem atraídas pelas imagens dos livros ilustrados, entretanto, para que ocorra a leitura das composições, principalmente no caso do livro de imagem, é necessário que o leitor se engaje para que consiga interpretar os sentidos da narrativa visual. Muitas vezes, os significados não estão claramente explicitados. Os livros de imagem demandam do leitor atenção e dedicação para assegurar a leitura e compreensão da ideia pretendida pelo autor/ilustrado, desafiando, inclusive no caso de muitos adultos. Assim, nossa experiência de proporcionar momentos de leitura de livros de imagens com leitores de públicos de crianças, jovens e adultos leva a crer que esses materiais, mesmo quando produzidos intencionalmente para crianças, podem proporcionar fruição e criar sentido para leitores de qualquer idade. No caso dos artistas ilustradores, a produção criativa representa um campo para a experimentação artística, à medida que promove a relação entre artes plásticas, cinema e literatura na construção das sequências. Para os leitores, proporciona um exercício de observação, de desfrute para os olhos, no qual se percorre os caminhos inseridos pelo artista na composição das imagens e nas lacunas deixadas na virada da folha na busca dos significados.

Os livros de imagem mostram que a riqueza desse tipo narrativo não se encaixa facilmente em categorias. Do ponto de vista do público a quem se destinam, a maior parte destes objetos são concebidos e direcionados como livros para crianças. Algumas, com narrativas mais complexas, arrojadas ou experimentais, são consideradas como sendo próprias para adolescentes ou adultos. Ainda outras produções, dado seu alto valor estético, são consideradas como livros de arte. O nosso objeto de pesquisa de doutoramento (ARAÚJO, 2016), no qual buscávamos compreender os 
meandros da criação artística do livro de imagem e sua relação com os leitores, foram as produções dirigidas para a infância.

Este artigo busca demonstrar como esse objeto editorial e sua especificidade de linguagem foi se delineando para se configurar no livro de imagem contemporâneo. Buscamos, desse modo, traçar um histórico demonstrando as origens dos livros de imagem no que concerne à forma, ao conteúdo e às intencionalidades neles implicados.

\section{Os precedentes dos livros de imagem}

As narrativas visuais encontram suas origens, de modo inegável, nas primeiras manifestações gráficas na história do homem. As pinturas rupestres, exemplo recorrente da relação do homem com o mundo a partir da expressão plástica, espalhadas em diferentes espaços e produzidas em diferentes épocas, dão indícios de como a produção de imagem representa um modo de comunicação narrativa e organização do homem com o mundo. Ao longo dos séculos, as imagens, assim como seu papel na sociedade, se transformaram. No Ocidente, os incunábulos, os livros de horas, assim como as Bíblias Pauperum, na Idade Média, foram pontos fundamentais na narração religiosa pela imagem, numa época em que grande parte da população era iletrada e dependia da imagem como âncora visual para relembrar histórias e exemplos de conduta. Anne Rowe (1996) afirma que os autores de livros de imagem dão continuidade a esta longa tradição quando resolvem visualmente os problemas de narração. Embora não possamos afirmar que estas manifestações tenham dado origem direta aos livros de imagem contemporâneos, é inegável que fazem parte de um importante legado de cultura visual.

A literatura destinada às crianças encontrava-se, em fins do século XIX, em processo de popularização. Os livros tornavam-se mais acessíveis à medida que os meios de produção os barateavam com edições mais singelas. Os livros deixaram de ser objetos raros reservados a uma elite intelectual. Além disso, outros materiais impressos também permitiam a circulação de informações. Blanchard (1969, p.76) afirma que os meios impressos eram um modo acessível de propagar ideias e imagens. Do mesmo modo que o livro 
enquanto objeto sofreu profundas transformações, os conteúdos também foram modificados, principalmente no que diz respeito ao sujeito social que estava se configurando - a criança (ARIÈS, 1981).

Apesar de considerarmos a importância da literatura infantil no desenvolvimento das narrativas visuais, existem diversos indícios que sugerem que as raízes do livro de imagem encontram-se num tipo de publicação distinto: os jornais ilustrados para adultos.

Os jornais tiveram grande repercussão no desenvolvimento da imagem impressa, já que o conteúdo deveria ser passado em poucas imagens. Com o surgimento dos jornais ilustrados no século XIX as imagens eram utilizadas como uma linguagem mais direta e lúdica para atingir (e dialogar com) o leitor. Existia nestes periódicos a presença de textos literários, curiosidades, conselhos, bem como publicidade. Em todas essas seções elencadas, a imagem estava presente como elemento retórico.

Wilhelm Busch e Adolf Oberländer, artistas alemães, passaram a publicar histórias sem palavras por volta de 1860, no periódico alemão Fliegende Blätter. Esses desenhistas haviam entrado em contato com as produções gráficas de Rodolf Töpffer, pedagogo e desenhista suíço, publicadas na Alemanha a partir de 1833, e com a linguagem que ele estava desenvolvendo. Gustave Doré, admirador do trabalho de Wilhelm Busch, teve um papel importante na mediação entre os desenhistas alemães e o suíço Töpffer.

Diante do sucesso deste modo de narrar, as histórias, assim como sua estrutura eminentemente visual, espalharam-se e passaram a ser reproduzidas em diferentes periódicos. Caran d'Ache, desenhista e caricaturista de origem russa radicado em Paris, tomou contato com as produções alemãs e levou para a França este gênero narrativo, por volta de 1880. Essas histórias passaram a ser publicadas sistematicamente em revistas e jornais franceses como Le Chat Noir e La Caricature, por exemplo (BOUDET, 2001). A característica geral dessas histórias é que, em uma ou duas páginas, a situação era colocada, desenvolvida e tinha um desfecho proposto, não tendo, necessariamente, alguma moral. Mariel Oberthür, no prefácio do livro Histoires sans paroles $d u$ Chat Noir, lembra que essas histórias não tinham caráter político, apesar de em determinados momentos, refletirem o contexto político vivenciado. O objetivo 
primeiro destas histórias era divertir e descontrair, sem o auxílio de nenhum tipo de texto escrito intervindo diretamente na narração (STEINLEN et al.,1998).

Essas narrativas foram bem recebidas entre os leitores; comprovando este fato, podemos encontrar as narrativas compiladas em livros, como é o caso de Des Chats: dessins sans paroles, de Steinlen, em 1898, ou ainda o projeto de livro de Caran d'Ache explicitado em carta para o diretor do jornal Le Fígaro, em 1894. Sua interessante proposta era a de criar um romance desenhado com 360 páginas de narrativas por imagem (GROENSTEEN, 1997).

Importante também refletirmos sobre a questão da autoria dessas histórias e seus autores. Esses jovens desenhistas e ilustradores tiveram um papel fundamental no desenvolvimento dessa linguagem visual, mas seus trabalhos não eram reconhecidos como arte. Gustave Doré, que muito contribuiu na construção desta linguagem gráfica, além de sua vasta produção como ilustrador, pintor e escultor, atualmente reconhecido como um grande artista, sofreu muita discriminação por ser um artista 'menor', que produzia "arte aplicada" e não Belas Artes. Contextualizando esses artistas, Mariel Oberthür afirma que a maioria era estrangeiro; muitas vezes utilizavam pseudônimos, eram provenientes de famílias pouco abastadas e produziam para os jornais como forma de sustento: "Esses artistas - que não eram admitidos nos salões de pintura, não estavam nas exposições oficiais das galerias de arte - buscavam seu lugar com os desenhos nos jornais" (OBERTHÜR, In: STEINLEN et al., 1998, tradução nossa).

Após a grande receptividade das narrativas por imagens, outros artistas passaram a explorar essa linguagem. Essas histórias foram amplamente exploradas por diversos desenhistas na França como Benjamin Rabier, Adolphe Willette e Fernand Fau. Fréderic Chaleil, na introdução do livro Histoires Sans Paroles de Caran d'Ache (2002, p.6), discorre sobre esse tipo narrativo e diz que

Esta fórmula de histórias curtas e mudas, em algumas vinhetas, a serviço de uma anedota, de um drama ou uma história cômica, fará sucesso em diversos jornais. Este processo de narrativa sequencial, de narrativa visual diferente da ilustração com 
legenda, é a mesma da história em quadrinhos. Sua aparência é quase um pequeno filme de animação que tem no enquadramento, o ritmo e a densidade falante das imagens. (tradução nossa)

No desenvolvimento da imprensa, diversos materiais foram sendo produzidos e, entre eles, os periódicos destinados às crianças. O folhetim francês Le journal des jeunes personnes, de 1832, foi o primeiro periódico para o público infantil. Era composto de muitos textos e algumas gravuras de má qualidade, mas representou o início de uma vasta produção literária para crianças, seguido de outros como Magasin Pittoresque e Le Journal des Enfants. Citamos os periódicos franceses, pois estes inspiraram a criação e serviram de modelo de alguns periódicos brasileiros.

Faz-se necessário, no entanto, refletir sobre as produções gráficas para adultos para compreender como elas influenciaram na concepção das produções para crianças e no desenvolvimento da linguagem gráfica narrativa.

No periódico alemão Fliegende Blätter, entre 1870 e 1890, diversos números traziam histórias por imagens. Um dos exemplos deste tipo de narração a partir de uma grafia sucinta (figura 1) indica como a imagem pode deter um conteúdo.

Subsequentemente, a continuação das narrativas publicadas nos jornais mostra que sofreram certo grau de refinamento, tanto narrativo quanto gráfico. $\mathrm{Na}$ revista Le rire, de 1895, pode-se ver oito imagens em sequência (figura 2), dispostas no sentido ocidental de leitura, da esquerda para a direita. Esta sequência de Caran d'Ache faz referência a uma narrativa visual de Wilhelm Busch, sobre o incômodo com pulgas.

Cabe notar que essas imagens eram publicadas em obras concebidas por e para adultos; supõe-se que faziam sucesso entre os leitores, dado o espaço que passaram a ocupar, assim como o aumento da frequência com que elas apareciam. As imagens publicadas nos periódicos populares tinham enorme aceitação entre os leitores fiéis a esta linguagem gráfica que se estabelecia no período, uma vez que ofereciam uma ruptura com o cotidiano, tornando-o mais descontraído (BERONÄ, 2009). 
Essas narrativas faziam uso da imagem como recurso para criticar a sociedade, assim como a política, e também como forma de lidar de maneira lúdica com as modificações que se passavam na sociedade.

Na sequência de Godefroy (figura 3), por exemplo, são abordadas, de maneira jocosa, as transições que sofriam as artes visuais e seus movimentos artísticos na Paris da Belle Époque.

\section{Transição entre o "para adulto" e o "para criança"}

Este tipo de linguagem em que a imagem comanda a narrativa, reivindicada atualmente como a origem das histórias em quadrinhos, configurase na segunda metade do século XIX e início do século XX. Antoine Sausverd ${ }^{1}$ propõe algumas relações entre as narrativas disponíveis em diferentes jornais e países e, sobretudo, como elas circulavam entre diferentes publicações e como seus temas eram reciclados. Optamos por trazer uma das reflexões que ele faz sobre essa linguagem específica com a história Arrosage public, no sentido que elas demonstram a transição do uso e função das narrativas visuais nos periódicos.

A primeira vez que essa história foi publicada foi na revista francesa $L e$ Chat Noir em 1885, sendo o autor Uzès, ilustrador e caricaturista francês. Trata-se de uma narrativa visual de seis imagens sequenciadas (Figura 4), composta de maneira intercalada, que exige do leitor um olhar atento na busca do significado da história.

Essa forma de composição que desloca o ponto de observação, em que os personagens oscilam entre o primeiro e segundo planos, demonstra a ampliação das possibilidades narrativas.

O mesmo roteiro foi publicado inúmeras vezes, reinventado por diferentes artistas. Um deles, publicado na revista alemã Fliegende Blätter, em 1886, cuja autoria é de Hans Schließmann, aparece também em um dos primeiros números da Revista Moderna, em 1897. Sob a rubrica História cômica e com legenda -um regador entupido-, fazia referência ao jornal alemão (Figura 5).

\footnotetext{
${ }^{1}$ Estudioso da literatura gráfica do século XIX e início do XX. Suas reflexões estão publicadas em formato digital, disponíveis em: 〈http://www.topfferiana.fr/>. Acesso em: set.2016. 
Trazia como mote a mangueira entupida pelo pé do menino, mas sob outro ponto de vista, o de cúmplice do brincalhão. Outra diferença nesta história é que o menino não é descoberto pelo adulto.

Dois anos depois, em 1899, a mesma história reaparece em Le petit français illustré, periódico destinado às crianças. Na transição de uma história cuja ideia inicial tenha sido impressa para um público adulto e, posteriormente, publicada para crianças, podemos supor que os editores tinham conhecimento do valor das imagens junto às crianças. Podemos pensar que eles tinham conhecimento de que essas sequências de imagens chegavam, de certo modo, às crianças ainda nos periódicos adultos, mediado pelos adultos ou por curiosidade própria.

No entanto, a questão da instrução, na virada do século $X X$, era uma preocupação crescente. Assim, o caráter moral na formação de bons valores sobrepunha-se na produção para crianças. A imagem publicada no periódico para crianças sofreu algumas modificações, ainda que não esteja incutida explicitamente uma moral, já que o menino não é descoberto, e por isso, não sofre nenhuma punição, mas foge da situação e não fica rindo como na história para adultos.

De acordo com Antoine Sausverd, o que parece uma simples apropriação da história de Uzès, representa, na verdade, uma situação típica da cidade na época -, apresentada com caráter além de lúdico, pedagógico. O autor francês Christophe divide a narrativa em quadros (figura 6), organizados de maneira clara. Apresenta primeiro as ferramentas do ofício do lavador e os procedimentos para a limpeza da via pública, assim como o trabalhador no primeiro plano. Essa narrativa em muito se assemelha às histórias em quadrinhos, que estavam se configurando como linguagem neste período, dada sua divisão esquemática em quadros, como forma de organizar a composição narrativa e facilitar a leitura.

Interessante notar que os livros de imagem contemporâneos parecem se apropriar em sua estrutura narrativa tanto da linguagem dos quadrinhos, como da linguagem cinematográfica. Nesse momento histórico, final do século XIX, em que estes gêneros linguísticos estão sendo desenvolvidos, percebemos 
que há um núcleo comum e que, considerando suas especificidades, as linguagens sempre interagiram. Segundo Blanchard,

No momento em que a fotografia triunfa, em que o realismo impõe seu código à pintura e à ilustração, os desenhistas livres, os caricaturistas (que se tornam humoristas) querem mostrar que há muito mais em seus desenhos que não dizem as legendas. Eles se dedicam, então, às "histórias sem palavras", que são como as charadas, jogos de espírito. (BLANCHARD, 1975, p. 144, tradução nossa)

Boudet (2000) busca estabelecer as diferenças entre as linguagens que utilizam o texto e a imagem ou apenas a imagem, nos distintos modos de relação. Para ele, diferentemente do desenho e das caricaturas, as narrativas visuais são caracterizadas pela sequência. Isso implica, no mínimo, duas imagens justapostas, em páginas distintas ou dispostas na mesma folha. $O$ fundamental é que haja vínculo narrativo entre as imagens para que a relação temporal/espacial se construa (p. 19). A contiguidade entre o antes e o depois oferece os elementos para o nexo narrativo.

Existem muitos exemplos de produção de ilustrações com caráter político ou satírico em publicações para adultos, que mostravam, no entanto, uma possibilidade de serem lidas por crianças. Nestas produções, podemos perceber que é tênue a fronteira que separa o que era produzido para adultos do que era produzido para crianças. Além disso, o exemplo na figura 6 demonstra que o uso do quadro separando as sequências, apesar de ser empregado com frequência, nunca foi obrigatório.

No Brasil, podemos tomar como exemplo as narrativas que ocasionalmente apareciam na Revista Moderna, destinada às mulheres, como uma fonte de diversão e informação. Provavelmente as crianças acessavam as histórias contidas nesses materiais. Seguindo a mesma estrutura de leitura, as narrativas visuais sequenciadas da esquerda para direita, com histórias e personagens da vida cotidiana, apareciam nos números da revista de maneira aleatória. Podem-se encontrar três pequenas histórias num mesmo número e duas edições sem esse tipo de história. Apesar de muitas vezes não ser possível definir a autoria, já que a assinatura está ausente ou ilegível, podemos perceber que existia um estilo narrativo por meio do qual os autores das imagens conseguiam ambientar a história e garantir os elementos que 
caracterizam a narrativa com poucos traços. Nesta página cômica, de 1899 (figura 7), podemos observar um casal flertando num contexto medieval. Consta uma pequena legenda - ou título - "Um engenhoso meio de correspondência". O adjetivo "cômico" da narrativa nos confirma qual é o propósito da história: divertir, provocar o riso ou fazer graça. Esta narrativa, de autoria de Benjamin Rabier, nos auxilia a seguir os caminhos da narração pela imagem nos periódicos adultos e a compreender a transição nas produções para as crianças.

A relação dos seres humanos com os animais era um tema recorrente nas histórias para adultos, a exemplo da figura 8, que apresenta a interação de um gato com um bebê (Figura 8). Os autores narravam essas histórias com poucos recursos. A curiosidade infantil em relação ao animal, a reação diante de uma investida do gato e o fim desastroso para ambos é o enredo da narrativa $O$ gato e o bebê, no qual também não se pode discernir se este texto serve de título ou legenda.

Essas histórias, embora impressas em mídia destinada para adultos, poderiam ser lidas também por crianças, apesar de seus temas não serem julgados como próprios para a formação infantil. Como suporte para essa discussão e para exemplificar esse período de transição, trazemos algumas imagens que foram publicadas no Journal Amusant, periódico para adultos, por Benjamin Rabier.

A prancha chamada $O$ pente foi publicada inicialmente neste jornal em 1904. A sequência incita reflexões sobre o uso dos elementos gráficos na composição, assim como a narratividade alicerçada exclusivamente pela imagem. Não há enquadramento divisor das imagens delimitando o espaço; em cada imagem os dois personagens são dispostos em diferentes ações que constroem a sequência (Figura 9): a menina coloca um líquido para o cachorro tomar, mas como ele é muito peludo, os pelos entram na tigela e ele fica sem enxergar. Então ela tira a tiara de sua cabeça e a coloca no cachorro. Mas quem fica despenteada é a menina. Esta história não correspondia com o modelo concebido de histórias para crianças no início do século $X X$, pois elas deveriam incentivar a boa educação dos leitores e por isso, neste momento não seria prudente publicá-la para crianças. 
Apenas um ano após a publicação da prancha Le peigne, a editora Frères Garnier inovou no mercado editorial para crianças ao publicar uma compilação das histórias por imagens de Rabier, publicadas anteriormente no jornal Amusant, no livro Écoutez-moil. A história original ganhou, além das cores (Figura 10), a seguinte legenda: "Como a menina Lili prestou um grande serviço ao seu amigo Azor".

O livro Écoutez-moi é composto por dezenas de pranchas de narrativas visuais. Muitas delas, porém, contêm diálogos ou descrições das ações em legendas representadas nas imagens, como a maioria das produções de histórias por imagens produzidas na época. Algumas, no entanto, fazem uso do texto escrito apenas como título ou legenda, como é o caso de "O pente". Outras, entretanto, não apresentam nenhum texto escrito, como no exemplo da narrativa do menino e o burro (Figura 11). Benjamin Rabier fazia uso de elementos do cotidiano como disparadores das narrativas, além de colocar crianças e animais como protagonistas. Como o próprio nome sugere, "Ouçame!", o livro pedia para ser narrado, oralizado e partilhado com alguém. Benjamin Rabier tinha um modo singular de narrar pela imagem, fosse para adultos ou crianças. As imagens seguintes (Figuras 11 e 12) dão-nos indícios do pensamento deste artista em relação às histórias por imagens e o modo como elas poderiam ser acessíveis - inclusive - para crianças.

As narrativas da obra de Rabier destoavam das obras produzidas até então para crianças, permeadas de moral. Defendemos que elas se colocam na contramão dos livros produzidos para crianças, pois analisamos que o autor não tinha o propósito de incutir bons hábitos nas crianças, nem tampouco incitar os maus. Se até então os livros típicos dirigidos para o público infantil tendiam ao ensinamento moral, desenhistas da comédie familiale, como Benjamin Rabier, representam um importante diferencial. Estes autores romperam com as normas vigentes ao mostrar que as crianças têm defeitos, que são curiosas, tirando-as do anonimato entediante das boas condutas. Eles criavam outro tipo de narrativa, muito mais instigante para as crianças. $O$ estilo narrativo de Rabier jogava com situações cotidianas em que as contradições e descobertas apareciam. Como é possível observar na leitura das três narrativas anteriores, o objetivo é a leitura por prazer, no jogo de encontrar 
relações entre um elemento e outro, tendo como temas histórias rotineiras. Mesmo na última história (Figura 12), a qual poderíamos entender como uma lição de moral diante da curiosidade infantil, o título sugere outro foco: "O reservatório", num instigante jogo entre palavra e imagem.

Benjamin Rabier tornou-se um autor conhecido no Brasil, pois suas histórias passaram a ser publicadas também na Revista O Tico Tico. Seus livros foram reproduzidos no Brasil, como o livro Écoutez-moi, que saiu com o título Escutem, em 1905. Benjamin Rabier, ao contrário de muitos artistas estrangeiros, não tinha seu nome de autor apagado quando sua produção foi reproduzida na O Tico Tico. Este periódico, conhecido como o responsável por introduzir as histórias em quadrinhos no Brasil, trazia, por vezes, histórias só por imagens, as quais denominava histórias sem palavras.

\section{Histórias em imagens: Produções para a criança}

Diante de uma demanda crescente por livros com imagens para as crianças, muitos editores passaram a produzir materiais de apoio pedagógico utilizando as narrativas visuais. Na constituição dessa produção literária para crianças somada às pautas de instrução pública - como alfabetizar muitas crianças ao mesmo tempo, materiais de incentivo à escrita e inculcação de moral -, pode-se perceber um investimento por parte das editoras, servindo às demandas da educação formal. Deste modo, a inserção da literatura produzida para crianças no sistema escolar teve como consequência a transformação dos conteúdos dos livros, que buscava nivelar a produção editorial com as expectativas da instrução formal.

Trazemos, como exemplo de produção e inserção das narrativas visuais no contexto pedagógico francês, o livro 30 histórias em imagens sem palavras para serem contadas pelas crianças, de 1902, concebido pelo professor Jean Perrot e desenhado pelo caricaturista Fernand Fau. Nas primeiras páginas, o autor sugere formas de oralizar a história, de modo que a cada página a criança construa uma frase na decodificação da imagem. Seus exemplos demonstram diferentes maneiras de descrever a mesma cena. No livro, fica evidente sua intenção de desenvolver, a partir da oralidade, a elocução e os 
"bons modos". 30 histórias em imagens apresentava-se como um livro pioneiro, de iniciação escolar, "que diminuiria as dificuldades do início dos estudos da criança, divertindo-a, fazendo-a interessar-se e falar" (PERROT, 1902, p. 2, tradução nossa).

As histórias, dispostas em três ou quatro quadros, tinham como caráter incutir princípios de boa conduta com forte apelo cívico. O bem-educado versus o mal-educado, o sujo versus o asseado, o corajoso versus o medroso, o honesto versus o ladrão, são apenas alguns dos exemplos das "histórias" feitas para ensinar e "divertir" as crianças. As atitudes negativas eram punidas, as boas atitudes eram enaltecidas.

Trazemos três narrativas como exemplo do teor das histórias. Numa primeira categoria, a má conduta é punida de qualquer modo, mesmo que seja pelo acaso. Em A curiosidade punida (Figura 13), em quatro imagens, podemos ver que a menina, ao tentar satisfazer sua curiosidade, foi punida pelo banco que caiu. A história é narrada com traço simples e preciso, com uso restrito das imagens, em que apenas os elementos pertencentes à narrativa estão presentes, neste caso, a menina, o banco e o armário com a caixa, objeto do desejo.

Em outra categoria, temos o exemplo a ser seguido como mote, num exercício das virtudes a serem desenvolvidas. Em apenas três imagens (Figura 14), a narrativa mostra o que pode acontecer com aqueles que são esforçados e com os preguiçosos.

O "bom menino" está estudando em duas das três imagens, enquanto o preguiçoso, (logo o "mau menino"), aparece dormindo na primeira cena e displicente na segunda. $\mathrm{Na}$ terceira imagem estão as recompensas que cada um merece, uma estrela de mérito para o trabalhador e o "canto do castigo" para o que nada fez. Temos que notar que "os bons modos" estão postos neste conjunto de imagens não só nas atitudes, mas na maneira que cada um se apresenta: o preguiçoso é também malvestido, despenteado e descuidado com seus materiais; já o trabalhador é bastante asseado e cuidadoso na maneira de portar-se. É interessante notar que o mesmo tipo de traço utilizado nos jornais satíricos e ilustrados está presente neste livro. 
Do conjunto de 30 histórias, encontramos apenas uma (Figura 15) que não se configura como moralista, ou pelo menos, de maneira tão intensa. Em duas imagens aparece uma brincadeira de crianças em que uma delas parou para amarrar o cadarço, causando uma queda coletiva, ou $A$ escorregada, como sugere o título.

Este modelo de livro, com forte apelo didático, não estava enquadrado nos padrões editoriais de literatura infantil, mas com o passar das décadas, podemos perceber que as fronteiras ficaram mais tênues, delineadas na necessidade de instrução de uma quantidade grande de alunos.

Os artistas continuaram produzindo as imagens para os jornais ilustrados ao longo do século $X X$, mas buscavam outros espaços de produção. Nesta perspectiva, é impossível desconsiderar o trabalho de certos artistas que, a partir principalmente de xilogravura e litogravura, produziam livros de narrativas visuais complexas. Neste grupo estão artistas como o belga Frans Masereel que publicou, em 1918, o romance gráfico 25 imagens da paixão de um homem (Figura 16), assim como o norte-americano Lynd Ward, e o alemão Otto Nückel, dentre outros. A artista gráfica tcheca Helena Bochořáková-Dittrichová, a partir do contato com esses romances gráficos em xilogravura, publicou 0 livro Childhood, em 1931. Nesta narrativa visual (Figura 17), ela retrata seu cotidiano no campo; pelo tema que aborda, foi considerado um livro para crianças (Beronä, 2009).

Apenas um ano após a publicação do livro de Dittrichová o, a autora norte-americana Ruth Carroll publicou nos Estados Unidos o livro What Whiskers did, de 1932, considerado por Eddy (2006) como o primeiro livro de imagem sem texto. Em 36 páginas, com duas cores, a narrativa visual (Figuras 18 e 19) desvela as aventuras de um cachorro que foge do dono num cenário de neve. O formato dessa história por imagens está muito próximo dos livros de imagem contemporâneos, quanto a suas dimensões $(22,5 \times 19 \mathrm{~cm})$, número de páginas e composição imagética. A editora Scholastic Book Service que a publicou fez sucessivas reedições. Alguns elementos nos dão indícios do uso desse material no contexto escolar, o primeiro sendo o nome da própria editora, seguido de uma dedicatória da autora para uma bibliotecária e um grupo de alunos. Na edição que possuímos (2ª impressão da $3^{\underline{a}}$ edição), um 
carimbo 'enquadra-a' como Fourth Grade, ou seja, destinado a alunos de quarta série do ensino fundamental, na equivalência do sistema educacional brasileiro.

Neste momento histórico, década de 1930, tanto o Brasil como a França tinham uma intensa produção de literatura infantil e dois homens despontavam como editores-autores: Monteiro Lobato e Paul Faucher. Monteiro Lobato, pesquisado em diversos estudos no Brasil, foi pioneiro na produção de livros para crianças no Brasil e extremamente importante na constituição de uma literatura infantil genuinamente brasileira. Paul Faucher, idealizador e responsável pelas edições do Père Castor, por sua vez, teve um papel fundamental na concepção moderna do livro para crianças. Suas produções possuíam um bom acabamento, com imagens de boa qualidade. Seu trabalho era fruto de muita pesquisa e tinha como característica marcante a interdisciplinaridade, já que entre seus colaboradores estavam psicólogos, artistas plásticos, designers, pedagogos, e profissionais do livro (ABREU, 2010). Além disso, suas produções tinham caráter intencionalmente pedagógico, comprometidas também com as concepções escolanovistas. No livro Bonjour Bonsoir, de 1934, que narra por imagem o cotidiano de um bebê, Faucher prefacia (ou prescreve) as lindas imagens de Nathalie Parain, demonstrando sua concepção em relação ao poder das imagens para com as crianças bem pequenas. Entendia que o reconhecimento das imagens era muito importante para elas.

As primeiras imagens impressionam profundamente o espírito da criança e ficam frequentemente fixadas em seu mundo interior. Se são feias, chapadas, sem cor, elas correm o risco de substituir a realidade por um clichê medíocre imposto à sua memória. Ao contrário, os desenhos que, tais como os de Nathalie Parain, expressam a imagem com plenitude, a cor e a poesia das coisas, só podem incitar a criança a melhor ver e a melhor sentir. (FAUCHER, In: PARAIN, 1934, tradução nossa).

Ao desenvolver uma metodologia de construção de livros para crianças e sua atuação, esse editor representou uma grande influência na produção moderna de literatura infantil, em que o comprometimento com a qualidade estética era pressuposto para a produção. 
Existe consenso na história da literatura infantil brasileira de que o livro Ida e Volta, de Juarez Machado, seja o primeiro livro de narrativa visual sem texto, publicado pela Editora Agir, em 1976. Este mesmo livro foi publicado um ano antes, na França, na seleção Histoires en images do Père Castor, pela Editora Flammarion, com o título Une aventure invisible. Ida e Volta marca o início de uma longa e densa produção de livros de imagem no cenário editorial brasileiro, que coincide, em certa medida, com uma tendência global. $\mathrm{Na}$ França, consideram o livro Les Aventures d'une petite bulle rouge, da artista italiana lela Mari, como o primeiro do gênero, publicado pela editora École des Loisirs, em 1968. Entretanto, o livro Des chats, do artista suíço naturalizado francês Steinlen, publicado 69 anos antes, é um livro de imagem que preenche todos os critérios para esse gênero.

\section{Considerações finais}

As narrativas visuais editadas entre o século $\mathrm{XIX}$ e $\mathrm{XX}$ dão-nos a dimensão do pensamento editorial concernente à infância e à função das imagens para crianças em cada período. Retomar as produções de narrativas visuais produzidas na virada do século $X X$ nos possibilita conhecer 0 desenvolvimento das narrativas por imagens que originaram as HQs e muito contribuíram para a constituição da linguagem gráfica dos livros de imagem. Acreditamos que a linguagem atual dos livros de imagem é resultante, desse modo, do atravessamento de alguns fatores cruciais: o encadeamento narrativo visual oriundo dessas literaturas gráficas produzidas entre os séculos XIX e XX, o desenvolvimento da linguagem cinematográfica, assim como o refinamento técnico advindo das artes plásticas e das ilustrações dos livros da literatura para crianças.

O tipo de história, a cadência narrativa e o uso do espaço físico da folha são elementos de extrema importância para análise das produções de narrativas visuais atuais, que refletem suas origens nas histórias sem palavras. A constante metamorfose da linguagem visual se observa tanto nas HQs quanto nos livros ilustrados. Em ambas, coexistem produções comerciais e produções autorais, com forte apelo estético. A transformação pela qual passou a literatura para crianças ao longo dos anos, nos diferentes países, converteu-a 
em uma linguagem plural: existem livros com todos os arranjos possíveis entre o texto, a imagem e o projeto gráfico. Em alguns, as imagens têm caráter narrativo; em outros, as imagens têm maior função de adorno; em alguns, o texto é irrelevante, em outros, essencial. Se nossa discussão é sobre o caráter narrativo exclusivo pela imagem sequenciada, acreditamos que os pioneiros das histórias por imagem contribuíram muito para o desenvolvimento desta linguagem peculiar. É inegável a herança dos ilustradores que constam na história da literatura infantil, mas não podemos ignorar esses artistas que produziam, sobretudo, para os jornais. A linha que separa as categorias de literatura para crianças e as HQs é bastante diluída, considerando a predominância da imagem e o teor narrativo. Isto é agravante no tocante às narrativas visuais, uma vez que a ausência de texto escrito e a composição em quadros cria uma mescla que resiste à categorização artificial. Um mesmo livro pode ser cadastrado como livro de imagem, romance gráfico ou $\mathrm{HQ}$, por exemplo. Salisbury e Styles discutem a esse respeito, comparando as composições visuais destas produções gráficas:

Livros de imagem estão surgindo como uma forma cada vez mais comum de literatura visual e, claro, têm a grande vantagem de serem universalmente legíveis. $O$ crescimento do interesse nos romances gráficos nos últimos anos tem impacto significativo nos livros para crianças. Em alguns casos, os limites destes e da arte sequencial, as HQs, tornaram-se confusas: com o uso de múltiplos quadros cada vez mais comum. (SALISBURY; STYLES, 2012, p. 98, tradução nossa)

Diante destas combinações plurais que compõem a literatura visual, em que, frequentemente o texto dialoga com a imagem, torna-se delicado estipular rígidos critérios, se o livro é dirigido para adultos ou crianças. Considerando, também, que essas produções são espaços experimentais de criação, os autores não estão exatamente fixados nas classificações presentes no mercado de edição. Encontram-se "HQs" com imagens de páginas duplas, sem balões e "livros de imagem" sequenciados em pequenos quadros, como diversas produções da brasileira Eva Furnari e da belga Anne Brouillard, para citar dois exemplos. O livro de imagem $A$ chegada do artista australiano Shaun Tan é também exemplo dessa obra híbrida, reivindicada tanto como "Literatura para Crianças" como "Histórias em Quadrinhos". Esta discussão reflete uma concepção de produção editorial que direciona os livros com imagens como 
obras para crianças e livros com texto como para adultos. As produções juvenis representam a passagem, em que a imagem míngua e o texto escrito domina e conduz (quase) totalmente a narrativa. As bibliotecas e livrarias defrontam-se de modo frequente com a classificação dessas obras em seus espaços; os editores, por sua vez, questionam-se sobre a pertinência deste ou aquele livro como literatura para crianças ou livros de arte.

Observamos anteriormente a pertinência de uma narrativa outrora para adulto como passível de fruição por uma criança. Entendemos que são decisões tomadas por adultos que determinam o que pode ser oferecido às crianças, de acordo com os princípios educativos e a concepção de infância em vigor. Para os livros de imagem contemporâneos, esses quesitos também são relevantes. Se o editor visa ao contexto escolar, seus conteúdos e temas serão mais brandos, com viés pedagógico mais explícito, na busca de produtos mais acessíveis aos padrões dos editais de compra, etc.

A concepção contemporânea do livro de imagem que aos poucos se delineia amplia e valoriza as possibilidades de criação e fruição. Assim como os teóricos defendem, os livros de imagem demonstram que constituem um gênero particular disponível para diferentes olhares e idades. Considerando as crianças leitoras, a predominância da imagem no desenvolvimento narrativo contribui para a aquisição de habilidades diversas; o gênero não se limita à aquisição da oralidade, mas corrobora para a aquisição da linguagem global, para a fruição estética e para a contemplação da arte.

\section{Referências bibliográficas}

ABREU, T. O livro para crianças em tempos de Escola Nova: Monteiro Lobato \& Paul Faucher. Instituto de Estudos da Linguagem - UNICAMP, Campinas, 2010. (Tese de doutorado)

ARAÚJO, H. Processos de criação e leitura de livros de imagem:interlocuções entre artistas e crianças. Instituto de Artes UNICAMP, Campinas, 2016. (Tese de Doutorado)

ARIÈS, P. História social da criança e da família. 2. ed. Tradução Dora Flaksman. Rio de Janeiro: LTC Editora, 1981.

BERONÄ, D. Le Roman graphique, des origines aux années 1950.

Paris: La Martinière, 2009. 
BLANCHARD, G. Bande dessinée, histoire des images de la préhistoire à nos jours. Bruxelles: Éd. Marabout, 1975.

BOUDET, Jean-Christophe. La bande dessinee muette depuis les annés soixante-dix en europe, aux etats-unis et au japon. Université Paris I Panthéon-Sorbonne, 2000. (Doutorado em História da Arte). Disponível em: http://www.du9.org/dossier/bande-dessinee-muette-1-la/. Acesso em 01/10/2014.

CHALEIL, F. Introdução. In: D’ACHE, CARAN. Histoire sans paroles. Les Éditions de Paris-Max Chaleil, 2002.

D’ACHE, C. Histoire sans paroles. Les Éditions de Paris-Max Chaleil, 2002.

EDDY, J. Bookwomen: creating an empire in children's book publishing, 1919_ 1939. Madison: University of Wisconsin Press, 2006.

FAUCHER, P. Prefácio. In: Parain, Bonjour Bonsoir. Paris: Flammarion, 1934.

GROENSTEEN, T. Histoire de la bande dessinée muette, $9^{\text {ème }}$ Art, n², CNBDI, Angoulême, janvier 1997.

MELOT, M. L'illustration: histoire d'un art. Genève: Éditions Skira, 1984.

OBERTHÜR, M. Prefácio. In: STEINLEN, Théophile et al. Histoires sans paroles du chat noir. Angoulême: Musée de la bande dessinée,1998.

PERROT, J. 30 histoires en images sans paroles à raconter par les petits: premier livre d'initiation et d'élocution. Paris: Librairie classique Fernand Nathan, 1902.

ROWE, A. Voices off: reading wordless Picture books. In: STYLES, Morag; BEARNE, E.; WATSON, V. (Orgs.). Voices off: texts, contexts and readers. London: Cassell, 1996.

STEINLEN, T. et al. Histoires sans paroles du chat noir. Angouleme: Musée de la bande dessinée, 1998.

STYLES, M.; BEARNE, E.; WATSON, V. Voices off. texts, contexts and readers._London: Cassell, 1996.

SALISBURY, M. ; STYLES, M. Children's picturebooks: the art of visual storytelling. London: Laurence King Publishers, 2012. 